\title{
Internal and external validity of Attention-Deficit Hyperactivity Disorder in a population-based sample of adults
}

\author{
J. J. SANDRA KOOIJ ${ }^{1}$, JAN K. BUITELAAR ${ }^{2 *}$, EDWIN J. VAN DEN OORD ${ }^{3}$, \\ JOHAN W. FURER ${ }^{4}$, CEES A. TH. RIJNDERS ${ }^{4,5}$ AND PAUL P. G. HODIAMONT ${ }^{4,5,6}$ \\ ${ }^{1}$ Parnassia, psycho-medical centre, Den Haag, The Netherlands $;{ }^{2}$ Department of Psychiatry, \\ University Medical Centre St Radboud, Nijmegen, The Netherlands $;{ }^{3}$ Faculty of Social Sciences, \\ University of Utrecht and Virginia Institute for Psychiatric and Behavioral Genetics, Richmond VA, USA; \\ ${ }^{4}$ Department of Social Medicine, University Medical Centre St Radboud, Nijmegen, The Netherlands; \\ ${ }^{5}$ GGZ Midden-Brabant, Tilburg, The Netherlands; ${ }^{6}$ Department of Health Psychology, University of Tilburg, \\ Tilburg, The Netherlands
}

\begin{abstract}
Background. Follow-up studies of childhood ADHD have shown persistence of the disorder into adulthood, but no epidemiological data are yet available.

Method. ADHD DSM-IV symptoms were obtained by self-report in an adult population-based sample of 1813 adults (aged 18-75 years), that was drawn from an automated general practitioner system used in Nijmegen, The Netherlands. The structure of ADHD symptoms was analysed by means of confirmatory factor analyses. Other data used in this report are the General Health Questionnaire (GHQ-28), information about the presence of three core symptoms of ADHD in childhood, and about current psychosocial impairment.
\end{abstract}

Results. The three-factor model that allowed for cross-loadings provided the best fit in the entire sample. This result was replicated across gender and age subsamples. Inattentive and hyperactivity symptom scores were significantly associated with measures of impairment, even after controlling for the GHQ-28. Subjects with four or more inattentive or hyperactive-impulsive symptoms were significantly more impaired than subjects with two, one and no symptoms. The prevalence of ADHD in adults was $1.0 \%(95 \%$ CI $0.6-1 \cdot 6)$ and $2.5 \%(1.9-3.4)$ using a cutoff of six and four current symptoms respectively, and requiring the presence of all three core symptoms in childhood.

Conclusions. These results support the internal and external validity of ADHD in adults between 18 and 75 years. ADHD is not merely a child psychiatric disorder that persists into young adulthood, but an important and unique manifestation of psychopathology across the lifespan.

\section{INTRODUCTION}

Attention-Deficit Hyperactivity Disorder (ADHD) is increasingly recognized as a diagnostic entity in adult psychiatric services. Follow-up studies of clinic-referred samples of children with ADHD indicate that the disorder

* Address for correspondence: Dr Jan K. Buitelaar, Department of Psychiatry, University Medical Centre St Radboud, PO Box 9109, 6500 HB Nijmegen, The Netherlands.

(Email: j.buitelaar@psy.umcn.nl) persists into adulthood in $10-60 \%$ of the cases (Weiss et al. 1985; Mannuzza et al. 1993). The considerable variation in level of persistence across studies probably reflects different definitions of remission from ADHD over time and symptom type (Biederman et al. 2000). There is further converging evidence that ADHD in adults can be reliably diagnosed (Murphy, 1996) and shows similar patterns as ADHD in children of psychiatric co-morbidity (Biederman 
et al. 1993), learning problems (Biederman et al. 1993; Barkley et al. 1996), family-genetic correlates (Faraone et al. 2000), brain correlates (Zametkin et al. 1990; Dougherty et al. 1999; Castellanos et al. 2001) and treatment response (Spencer et al. 1995; Wilens et al. 1996).

In spite of an accumulating database on ADHD in adults, a number of pivotal issues have yet to be addressed. The first one is whether the symptoms of ADHD in adults fit into the same two-factor [inattention (IA) and hyperactivity-impulsivity (HI)] or three-factor models [inattention (IA), hyperactivity $(\mathrm{H})$, and impulsivity (I)] that have been found in children and are reflected in the current conceptualization of ADHD in DSM-IV. The 18 symptoms of DSM-IV ADHD are spread over three separate dimensions: IA (nine symptoms), $\mathrm{H}$ (six symptoms) and I (three symptoms). Furthermore, DSM-IV describes three types of ADHD: combined type (at least six IA and at least six $\mathrm{H}$ and $\mathrm{I}$ or $\mathrm{HI}$ symptoms), inattentive type (at least six IA symptoms) and hyperactive-impulsive type (at least six HI symptoms). This scheme of three subtypes was chosen largely on the basis of a number of exploratory factor analytical studies using ADHD symptoms contained in DSM-III and DSM-III-R (Lahey et al. 1988; Pelham et al. 1992; Baumgaertel et al. 1995). These studies provided support for two independent factors: IA and HI.

A second issue is that data on prevalence and impairment of functioning of adult ADHD obtained directly from community studies are absent. Among a convenience sample of 720 adults applying for or renewing their driver's licence, the occurrence of self-reported DSM-IV ADHD symptoms amounted to an overall prevalence of adult ADHD of $4.7 \%(1.3 \%$ inattentive type, $2.5 \%$ hyperactive-impulsive type, and $0.9 \%$ combined type) (Murphy \& Barkley, 1996). The cutoff of six or more out of nine criteria for ADHD in DSM-IV was derived by calibrating measures of impairment of functioning versus symptom counts (Lahey et al. 1994).

This study utilized self-report data on current ADHD DSM-IV symptoms in a Dutch population-based sample of adults between 18 and 75 years of age, to address the issues detailed above.

\section{METHOD}

\section{Sample}

The data were collected in the context of the Nijmegen Health Area Study-2 (NHA-2) that was designed to assess the prevalence and distribution of psychiatric morbidity in the region of Nijmegen, The Netherlands. The NHA-2 is based on a probability sample of subjects registered in the practice of a general practitioner (GP). Since nearly every inhabitant of The Netherlands is registered with a GP practice, the degree of this registration is equivalent to that of the register offices. A random sample of $5 \%(n=4517)$ of the total population of 80315 subjects between 18 and 75 years old was asked to participate. From those, $45.4 \% \quad(n=2049)$ gave written informed consent. In the end 1813 subjects were available for data collection between September 1997 and March 1998; this constitutes the study sample. The composition of the sample by gender and age was as follows: men $(44 \cdot 7 \%)$, women $(55 \cdot 3 \%)$; age: $18-29$ years $(14.9 \%), 30-44$ years $(37.5 \%), 45-59$ years $(30 \cdot 0 \%), 60-75$ years $(17 \cdot 7 \%)$. Men and younger subjects were under-represented in the study sample, compared to the general population of The Netherlands [Central Bureau of Statistics (CBS), 1997]. Accordingly, the prevalence data were weighted to approximate the distribution of these demographic variables in the general population. A further comparison of participants and non-participants showed no differences in prescription of psychotropic medication by the GPs. This indicates that selection bias with respect to psychiatric disorders was unlikely.

\section{Procedure and measures}

Experienced interviewers of the Institute of Applied Sociology in Nijmegen interviewed the study sample. The interview covered sociodemographic variables, the General Health Questionnaire (GHQ; Goldberg \& Williams, 1988), variables on psychosocial impairment and a Dutch version of the ADHD DSM-IV rating scale (DuPaul et al. 1998). Almost 1800 questionnaires were completed and returned (response rate 99\%). Demographic variables registered were: age, gender and income.

The GHQ-28 was used as a measure of general liability to psychopathology. Psychosocial 
impairment was measured by four items. The items about the current presence of selfperceived psychological disorder and the current use of medication for psychological disorder were binary coded (yes/no). The third item asked about whether mental health problems did interfere with social contacts over the past 4 weeks, and was coded on a five-point scale ('not at all' to 'very much'). The fourth item asked about whether mental health problems did interfere with social activities over the past 4 weeks, and was coded on a sixpoint scale ('not at all' to 'always'). We computed an aggregated measure of psychosocial impairment by averaging the scores of the four single items after these had been rescaled to unity. The range of this aggregated measure is from 0 to 1 , with higher scores reflecting greater overall impairment. Cronbach's alpha was $0 \cdot 72$

A Dutch version of the ADHD DSM-IV rating scale was constructed using the 18 DSM-IV items for ADHD (DuPaul et al. 1998). Symptoms were reported over the last 6 months. To facilitate a reliable self-report, five complex items were reformulated in two single statements. IA item 1 was reformulated into 'fail to give close attention to details in work' and 'make careless mistakes in work'; IA item 4 into 'difficulty following through on instructions' and 'fail to finish activities or work'; HI item 1 into 'fidget with hands or feet' and 'squirm in seat'; HI item 3 into 'feel restless' and 'get bored quickly'; and HI item 4 into 'difficulty to relax in leisure time' and 'holidays or leisure time in busy and noisy environment'. Each item was to be rated on a four-point scale $(0=$ 'rarely or never', $1=$ 'sometimes', 2 ='often', 3 = 'very often') based on current behaviour within the past 6 months. In rendering each item on the scale, the word 'often' was eliminated from the wording of each item in the original DSM-IV list. IA and HI items alternated in their sequence listed on the scale. We added three items based on the retrospective recall of the presence of inattentive, hyperactive and impulsive behaviour in childhood, around 7-8 years of age. The childhood items were also rated on a four-point scale $(0=$ 'rarely or never', $1=$ 'sometimes', 2 ='often', $3=$ 'very often'). Thus, the self-report questionnaire consisted of 26 items in total, with 23 items on current
ADHD symptoms and three childhood items. A symptom was considered as present if the answer given to the item was 'often' or 'very often' (score of 2 or 3). In analyses on prevalence, the 23 current item scores were recalculated to the original 18 DSM-IV items. For childhood symptoms a score 'often' or 'very often' on all three items was considered clinically relevant and taken as an index of the presence of ADHD in childhood. This turned out to be the case for $2 \cdot 8 \%$ of the population.

\section{Statistical analysis}

To avoid a loss of information due to the required listwise deletion in some of our analyses, missing responses (in 42 subjects up to four missing items per subject) were replaced by imputed values using the EM algorithm as implemented in SPSS 9.0 (SPSS Inc., Chicago, IL, USA) (Dempster et al. 1977). A comparison between the correlation matrix computed using the imputed values versus the correlation matrix computed using pairwise deletion showed that this hardly affected the input matrix (mean difference $=-0 \cdot 003$, s.D. of mean difference $=$ 0.007).

The factor structure of the 23 current ADHD symptoms was examined by confirmatory factor analyses using the computer program Mplus (Múthen \& Múthen, 1998). Five competing models were evaluated. The first model assumed that all items loaded on a single common factor. The second model made a distinction between IA and HI subtypes. To account for the fact that subjects may suffer from both subtypes (i.e. the combined type), the IA and HI factors were allowed to correlate. The second model assumed a perfect simple structure, in which the items only loaded on the factor that they were supposed to measure. A third model included a common IA and HI factor similar to the second model, but allowed for cross-loadings. The fourth model included the IA factor and in addition specified separate factors for the $\mathrm{H}$ and I symptoms as distinguished in DSM-IV and assumed a perfect simple structure. To deal with co-morbidity, the correlations among the three factors were estimated. The fifth model included the three common factors IA, H and I like the fourth model, but allowed for crossloadings. It is not possible to estimate all 
Table 1. Standardized factor loading in best-fitting simple structure model

\begin{tabular}{|c|c|c|c|c|c|}
\hline & Item & $\begin{array}{l}\text { DSM-IV } \\
\text { domain }\end{array}$ & $\begin{array}{c}\text { IA } \\
\text { factor }\end{array}$ & $\begin{array}{c}\mathrm{H} \\
\text { factor }\end{array}$ & $\begin{array}{c}\text { I } \\
\text { factor }\end{array}$ \\
\hline $14^{\mathrm{a}}$ & Difficulty organizing tasks and activities & IA & $0 \cdot 70$ & $-^{\mathrm{b}}$ & $-0 \cdot 17$ \\
\hline 22 & Forgetful in daily activities & IA & 0.66 & - & - \\
\hline 18 & Lose things necessary for tasks or activities & IA & 0.60 & - & - \\
\hline 5 & Difficulty sustaining attention in tasks & IA & 0.59 & $0 \cdot 24$ & $-0 \cdot 17$ \\
\hline 16 & Avoid or reluctant to engage in tasks requiring sustained mental effort & IA & 0.59 & $0 \cdot 10$ & $-0 \cdot 12$ \\
\hline 10 & Difficulty following through on instructions & IA & 0.57 & - & - \\
\hline 11 & Fail to finish activities or work & IA & 0.57 & - & $-0 \cdot 10$ \\
\hline 3 & Make careless mistakes in work & IA & $0 \cdot 50$ & - & - \\
\hline 20 & Easily distracted & IA & 0.43 & $0 \cdot 30$ & - \\
\hline 7 & Do not listen to what is being said & IA & $0 \cdot 37$ & - & $0 \cdot 24$ \\
\hline 1 & Fail to give close attention to details in work & IA & $0 \cdot 34$ & - & - \\
\hline 8 & Feel restless & $\mathrm{H}$ & $0 \cdot 25$ & $0 \cdot 63$ & $-0 \cdot 17$ \\
\hline 12 & Difficulty to relax in leisure time & $\mathrm{H}$ & $0 \cdot 26$ & $0 \cdot 56$ & $-0 \cdot 24$ \\
\hline 4 & Squirm in seat & $\mathrm{H}$ & - & $0 \cdot 54$ & - \\
\hline 15 & 'On the go' or act as if 'driven by a motor' & $\mathrm{H}$ & - & $0 \cdot 52$ & - \\
\hline 9 & Get bored quickly & $\mathrm{H}$ & $0 \cdot 21$ & $0 \cdot 51$ & $-0 \cdot 21$ \\
\hline 2 & Fidget with hands or feet & $\mathrm{H}$ & - & $0 \cdot 43$ & - \\
\hline 17 & Talk excessively & $\mathrm{H}$ & $-0 \cdot 13$ & $0 \cdot 35$ & 0.33 \\
\hline 13 & Holidays or leisure time in busy and noisy environment & $\mathrm{H}$ & - & $0 \cdot 30$ & - \\
\hline 6 & Leave seat in situations where it is inappropriate & $\mathrm{H}$ & $0 \cdot 18$ & $0 \cdot 27$ & - \\
\hline 23 & Interrupt or intrude on others & I & - & - & 0.79 \\
\hline 19 & Blurt out answers before questions have been completed & I & - & $0 \cdot 15$ & 0.64 \\
\hline 21 & Difficulty awaiting turn & I & $0 \cdot 13$ & $0 \cdot 22$ & $0 \cdot 34$ \\
\hline
\end{tabular}

a Listing of item in the Dutch ADHD DSM-IV rating scale.

b - Indicates that factor loading is fixed to zero; IA, inattention; H, hyperactivity; I, impulsivity.

(cross-)loadings and identifying constraints need to be imposed via a rotation criterion (Jöreskog, 1978).

To evaluate the factor models, multiple-fit criteria were used. First, the Satorra-Bentler rescaled $\chi^{2}$ was applied (Satorra \& Bentler, 1988). Secondly, Akaike's Information Criterion (AIC) was used (Akaike, 1987; Williams \& Holahan, 1994). Finally, we used the Tucker-Lewis Index (TLI) and the Comparative Fit Index (CFI) that reflect the improvement in fit compared to a baseline model (Marsh et al. 1988; Múthen \& Múthen, 1998; Bentler, 1990). The TLI and CFI usually range from 0 to 1 and, similar to the AIC, apply a penalty function for estimating more parameters. Larger values imply a better fit so that the model with the TLI and CFI closest to 1 was selected.

The relationships between the ADHD DSM-IV symptom domains of IA and HI and measures of psychosocial impairment were examined by logistic regression, multiple linear regression, analysis of covariance (including GHQ-28 as covariate) and Receiver-operating characteristic (ROC) analyses, using SPSS 9.0.

\section{RESULTS}

\section{Confirmatory factor models}

The results of the confirmatory factor analyses show that the three-factor model that allowed for cross-loadings was selected as the best-fitting model by all fit indices. Thus, this model had the smallest AIC and the largest TLI and CFI $\left(\chi^{2}=723.73, \quad \mathrm{df}=206, \quad \mathrm{AIC}=311 \cdot 73, \quad \mathrm{TLI}=\right.$ $0.926, \mathrm{CFI}=0.939)$. A comparison with the three-factor cross-loading model showed that on the basis of the degrees of freedom, the AIC and the TLI, this latter model should be preferred in terms of parsimony and fit.

The standardized factor loadings in the bestfitting simple structure are shown in Table 1. To compose this table, the items were allocated to the factor on which they had the highest loading. Next, the loadings of each factor were sorted in descending order. Table 1 shows that all items loaded highest on the factor they were supposed to measure according to the description in DSM-IV. Furthermore, when a loading of 0.3 was used as a cut-off above which an item was viewed as a reliable indicator of that factor, all these factor loadings were larger 
than $0 \cdot 3$, except for $\mathrm{H}$ item 6 'leave seat'. Finally, only two items (IA item 'easily distracted' and $\mathrm{H}$ item 'talks excessively') had cross-loadings of $\geqslant 0 \cdot 3$. Thus, the vast majority of items possessed the desirable property that they were indicators of the intended factor only.

In the best-fitting simple structure the estimated correlations between IA and $\mathrm{H}$, IA and I, and $\mathrm{H}$ and $\mathrm{I}$ were $0.57,0.50$, and 0.47 respectively. This indicated that on the one hand the three factors shared a proportion of their variance, and on the other tapped different aspects of ADHD. Cronbach's alphas for IA, H, and I were $0 \cdot 83,0 \cdot 75$, and $0 \cdot 72$ respectively.

\section{Replications using tetrachoric correlations, across gender and age subgroups}

To study the robustness of the results the analyses were repeated using polychoric correlations in combination with an asymptotically distribution free estimation method (ADF; Browne, 1984). The three-factor cross-loading model was again selected by all fit indices as the best-fitting model. This replicated the results with the maximum-likelihood approach and provided support for the robustness of the findings.

The analyses were also performed for males and females and for two age groups of the same size separately. The three-factor cross-loading model was selected again as the best-fitting model in all groups and by all fit indices. To examine whether in addition to the general model the parameter estimates were also identical, we fitted the best-fitting simple structure model with and without equality constraints across groups. For the comparison between males and females constraining the parameters to be equal $\left(\chi^{2}=1051 \cdot 151, \mathrm{df}=482, \mathrm{AIC}=87 \cdot 15\right.$, $\mathrm{TLI}=0.931$, CFI $=0.935)$ did not yield a much poorer fit than estimating different parameters in each group $\left(\chi^{2}=959 \cdot 24, \mathrm{df}=412, \mathrm{AIC}=\right.$ $135.24, \quad$ TLI $=0.923, \quad C F I=0.937)$. This suggested that the parameter estimates were similar in males and females. For the comparison between the young and old cohort the fit indices were $\chi^{2}=1086 \cdot 13, \mathrm{df}=482, \mathrm{AIC}=$ $122 \cdot 13, \mathrm{TLI}=0 \cdot 925, \mathrm{CFI}=0.928$ for the model assuming equal parameters, and $\chi^{2}=959 \cdot 24$, $\mathrm{df}=412, \mathrm{AIC}=123.98, \mathrm{TLI}=0.922, \mathrm{CFI}=0.936$ for the model without equality constraints.
Table 2. Correlations between ADHD symptom factors in adults and demographic characteristics, GHQ, and psychosocial impairment

\begin{tabular}{|c|c|c|c|}
\hline & IA & $\mathrm{H}$ & I \\
\hline \multicolumn{4}{|l|}{ Demographic characteristics } \\
\hline Gender $($ male $=0$, female $=1)$ & $-0 \cdot 01$ & $0 \cdot 09 *$ & $0 \cdot 04$ \\
\hline Age & $0 \cdot 04$ & $-0 \cdot 16^{*}$ & $-0 \cdot 01$ \\
\hline Income & $-0 \cdot 08^{*}$ & $-0 \cdot 07^{*}$ & $0 \cdot 00$ \\
\hline \multicolumn{4}{|l|}{ General Health Questionnaire } \\
\hline Total score GHQ-28 & $0 \cdot 45^{*}$ & $0 \cdot 48 *$ & $0 \cdot 24^{*}$ \\
\hline Somatic symptoms & $0 \cdot 39 *$ & $0 \cdot 43^{*}$ & $0 \cdot 21^{*}$ \\
\hline Anxiety and sleep problems & $0 \cdot 39 *$ & $0 \cdot 46^{*}$ & $0 \cdot 24^{*}$ \\
\hline Social dysfunctioning & $0 \cdot 35^{*}$ & $0 \cdot 29 *$ & $0 \cdot 14^{*}$ \\
\hline Depression & $0 \cdot 38^{*}$ & $0 \cdot 40^{*}$ & $0 \cdot 21 *$ \\
\hline \multicolumn{4}{|l|}{$\begin{array}{l}\text { Childhood ADHD symptoms } \\
\text { (retrospective) }\end{array}$} \\
\hline Inattention & $0 \cdot 25^{*}$ & $0 \cdot 36^{*}$ & $0 \cdot 25^{*}$ \\
\hline Hyperactive & $0 \cdot 39 *$ & $0 \cdot 38 *$ & $0 \cdot 24^{*}$ \\
\hline Impulsive & $0 \cdot 29 *$ & $0 \cdot 33^{*}$ & $0 \cdot 29^{*}$ \\
\hline \multicolumn{4}{|l|}{ Impairment } \\
\hline Psychological disorder & $0 \cdot 29 *$ & $0 \cdot 32 *$ & $0 \cdot 15^{*}$ \\
\hline $\begin{array}{l}\text { Medication for psychological } \\
\text { disorder }\end{array}$ & $0 \cdot 22 *$ & $0 \cdot 27^{*}$ & $0 \cdot 12^{*}$ \\
\hline Social contacts & $0 \cdot 31^{*}$ & $0 \cdot 34^{*}$ & $0 \cdot 17^{*}$ \\
\hline Social activities & $0 \cdot 31^{*}$ & $0 \cdot 30^{*}$ & $0 \cdot 14^{*}$ \\
\hline
\end{tabular}

IA, inattention; $\mathrm{H}$, hyperactivity; I, impulsivity. $* p<0 \cdot 05$.

These fit indices were not completely consistent, with the CFI suggesting age differences whereas the TLI and AIC did not.

\section{External validity}

The external validity of the ADHD symptom factors was studied via correlations with demographic variables, the GHQ, retrospective selfratings of ADHD symptoms in childhood, and self-rated psychosocial impairment (see Table 2). The number of $\mathrm{H}$ symptoms was somewhat higher in women and in subjects of young age, and both $\mathrm{H}$ and IA symptoms were more present in subjects with low income. The effect of gender on the number of $\mathrm{H}$ symptoms remained after controlling for GHQ-28 since women had also higher scores on the GHQ (partial correlation $0.08, p<0.001)$. All correlations involving the GHQ scales were significant. Correlations were larger for IA and $\mathrm{H}$ symptoms than for I symptoms. The largest correlations were found for the GHQ-28 total score. The correlations with the IA, H, or I childhood symptoms suggested some extent of specificity. That is, $\mathrm{H}$ showed the highest correlation with the $\mathrm{H}$ childhood symptom, and I with the I childhood symptom. 
Table 3. Logistic regression of self-assessed presence of psychological disorder on $A D H D$ symptom counts with and without the GHQ-28

\begin{tabular}{lrrccc}
\hline \hline & \multicolumn{1}{c}{$B$} & S.E. $b$ & Wald statistic & df & $p$ \\
\hline Without GHQ-28 & & & & & \\
H & $0 \cdot 196$ & $0 \cdot 030$ & $41 \cdot 795$ & 1 & $0 \cdot 000$ \\
IA & $0 \cdot 124$ & $0 \cdot 025$ & $25 \cdot 021$ & 1 & $0 \cdot 000$ \\
I & -0.081 & $0 \cdot 069$ & $1 \cdot 408$ & 1 & $0 \cdot 235$ \\
With GHQ-28 & & & & & \\
H & $0 \cdot 123$ & $0 \cdot 034$ & $13 \cdot 194$ & 1 & $0 \cdot 000$ \\
IA & $0 \cdot 066$ & $0 \cdot 027$ & $6 \cdot 229$ & 1 & $0 \cdot 013$ \\
I & $-0 \cdot 017$ & $0 \cdot 073$ & $0 \cdot 053$ & 1 & $0 \cdot 819$ \\
GHQ-28 & $1 \cdot 868$ & $0 \cdot 228$ & 66.971 & 1 & $0 \cdot 000$ \\
\hline \hline
\end{tabular}

IA, inattention; H, hyperactivity; I, impulsivity.

The final set of correlations indicated that ADHD symptoms are associated with impaired psychosocial functioning. Thus, subjects with many symptoms were more likely to report having a psychological disorder, receive medication for a psychological disorder, and indicate that their disorder affects their social contacts and activities negatively.

To examine whether IA, $\mathrm{H}$, and I made unique contributions to the prediction of psychosocial impairment scores or reflected a general ADHD liability, logistic regression and multiple linear regression models were built. Results were remarkably consistent showing significant and unique contributions of the IA and $\mathrm{H}$ factor to all four impairment measures (see Table 3 for the prediction of self-assessed psychological disorder). This indicated that distinction between IA and $\mathrm{H}$ symptoms was clinically meaningful. The I symptoms showed a small negative effect that was significant in approximately half of the regression equations.

Next, we explored whether the ADHD symptom factors are merely an indicator of a general liability for psychopathology or reflect a specific liability. To this end, the GHQ-28 as a measure of the general liability was included with the ADHD symptom factors in a logistic regression analysis with the self-assessed presence of a psychological disorder as dependent variable (Table 3 ). The results showed that the effects of IA and $\mathrm{H}$ remain significant, even after the inclusion of the GHQ-28. The ADHD symptom factors appear to capture a unique aspect of psychopathology that is not measured by the GHQ.

\section{Impairment and prevalence rates}

To examine the relationships between ADHD symptoms and impairment of functioning and to determine the prevalence of ADHD in the present sample, the original 18 DSM-IV items were retrieved. A problem in the study of ADHD in adults is the choice of the diagnostic threshold. One option is to use the threshold of six out of nine symptoms for each domain of IA and HI, as specified for children in DSM-IV. However, children are normally more active and have more difficulty in concentrating than adults, leading to a higher base-rate of symptom levels in children than in adults. One may, therefore, argue that the threshold should be set lower in adults, who might experience impairment at fewer symptoms. To estimate the diagnostic threshold in adults, the number of IA and HI symptoms was plotted versus the aggregated measure of impairment, while using the GHQ28 as a covariate (Fig. 1). Analyses of covariance (ANCOVAs) (between-subjects factor 'number of symptoms' in seven levels: 6 or more symptoms, 5, 4, 3, 2, 1, and 0 symptoms; and GHQ-28 as covariate) indicated that subjects with four or more IA symptoms had impairment scores that were significantly increased compared to lower levels of 2,1 or 0 IA symptoms [overall model $F(7,1709)=144.631, p<$ $0 \cdot 000$, 'number of symptoms' $F(6,1709)=$ $7 \cdot 371, p<0 \cdot 000]$. In a similar analysis of covariance, subjects with four or more HI symptoms were significantly more impaired than subjects with lower levels of 3,2, 1 and 0 HI symptoms [overall model $F(7,1709)=153.963, p<0.000$, 'number of symptoms' $F(6,1709)=10.973$, $p<0 \cdot 000]$. Subsequent ANCOVAs that included gender and age in addition to GHQ-28 as covariates, and ANCOVAs for men and women and for young and old subjects separately replicated the finding of a cutoff of four symptoms. Once IA and HI symptom counts had been included, regression models indicated that impairment was just linearly related to counting IA symptoms, with no evidence of any additional impairment at the cutoff of four symptoms (Fig. 1). For HI symptoms, however, a cutoff of four symptoms was associated with additional impairment $(p<0 \cdot 05)$.

We further explored the relationships between ADHD symptoms and impairment in 

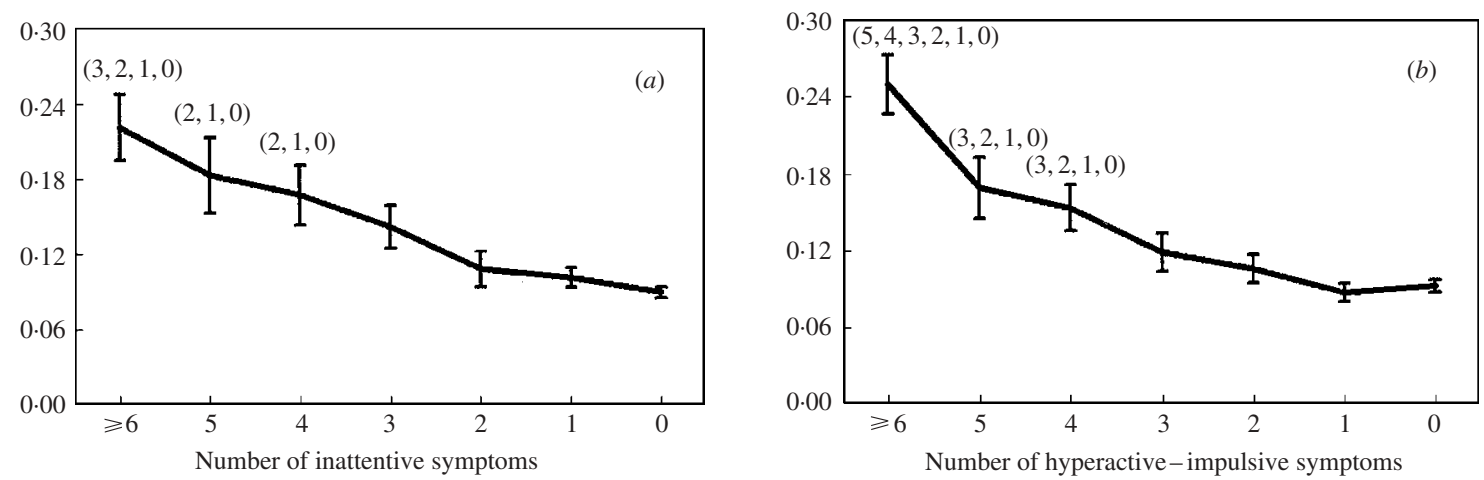

FIG. 1. Composite measure of impairment by $(a)$ number of inattentive symptoms and $(b)$ hyperactive-impulsive symptoms, with GHQ-28 as covariate. Figures within parentheses indicate that groups with four or more inattentive or hyperactive-impulsive symptoms were significantly more impaired than, for example subjects with 2,1 and 0 symptoms $(p<0 \cdot 05$, least-square differences).
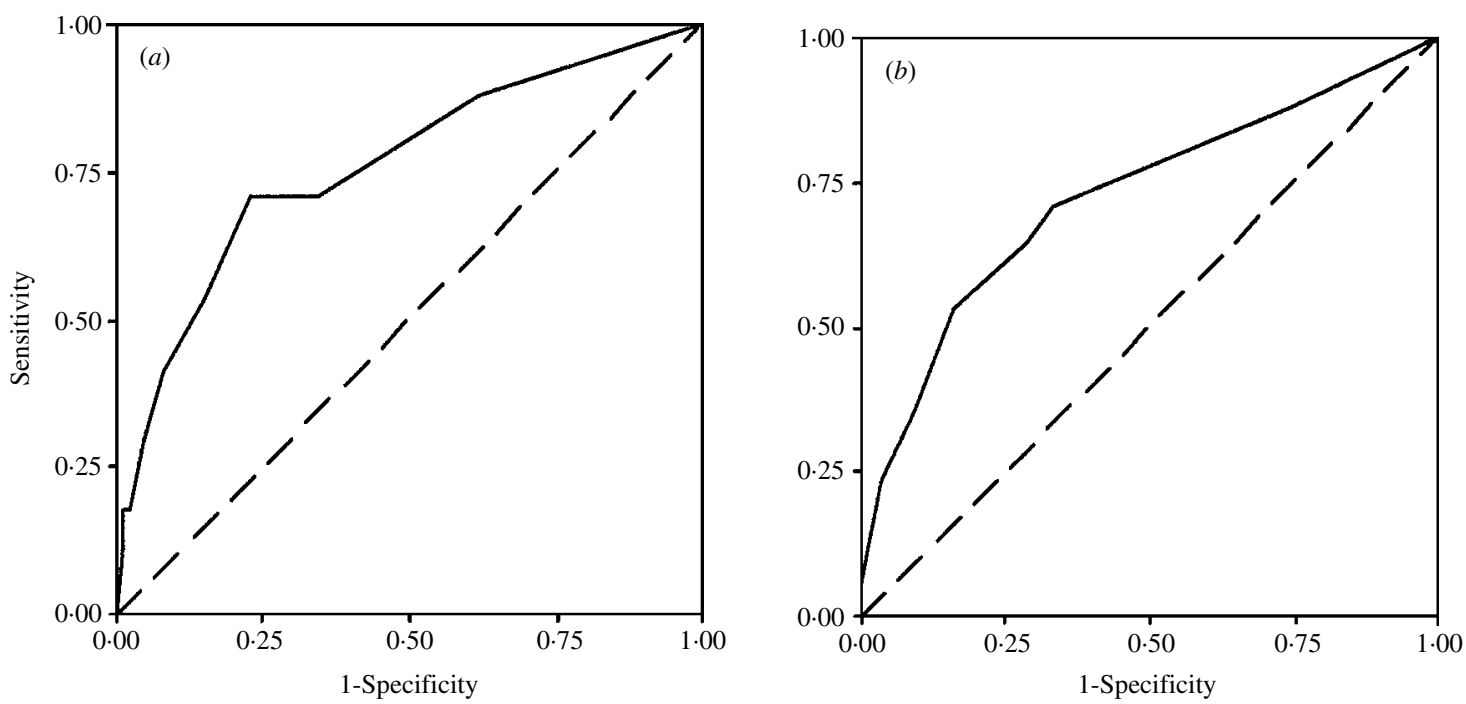

FIG. 2. ROC curves of (a) number of inattentive symptoms and (b) number of hyperactive-impulsive symptoms versus $95 \%$ percentile cutoff of impairment.

ROC analyses, using the 95th percentile of impairment as cut-off point (Fig. 2). The area under the curve (AUC) for the number of inattentive, and hyperactive-impulsive symptoms respectively was $0.760(p<0.01 ;$ S.E. $=0.069$, $95 \%$ CI $0.624-0.895)$ and $0.724 \quad(p<0.01$; S.E. $=0 \cdot 074,95 \%$ CI $0 \cdot 579-0 \cdot 870)$. The optimal trade-off between sensitivity and specificity for both inattentive and hyperactive-impulsive symptoms was obtained at the threshold of three symptoms (inattentive symptoms: sensitivity $=$ 0.71 , specificity $=0.77$; hyperactive-impulsive symptoms: sensitivity $=0 \cdot 71$, specificity $=0 \cdot 67$ ).
On the basis of these analyses, it seems justified to conclude that on average the presence of four or more ADHD symptoms of either IA or HI is associated with significantly increased self-perceived psychosocial impairment, even after controlling for the level of general psychopathology as reflected in the GHQ-28.

By the application of a cutoff of six current ADHD symptoms and the presence of all three symptoms in childhood, a weighted prevalence of overall ADHD of $1.0 \%(95 \%$ CI $0 \cdot 6-1 \cdot 6)$ was obtained. The prevalences of the subtypes were $0.2 \%$ for the inattentive, $0.5 \%$ for the 
hyperactive-impulsive and $0.3 \%$ for the combined subtype. There was no significant gender effect using this cutoff. A cutoff of four current ADHD symptoms and the presence of all three symptoms in childhood implied a weighted prevalence of ADHD of $2.5 \% \quad(95 \%$ CI $1 \cdot 9-3 \cdot 4$ ), including $0.3 \%$ for the inattentive, $1.2 \%$ for the hyperactive-impulsive and $1.0 \%$ for the combined subtype. Using the cutoff of four symptoms, women had a higher prevalence of ADHD than men [odds ratio (OR) $2 \cdot 6,95 \%$ CI $1 \cdot 4-4 \cdot 7, p<0 \cdot 05]$. There were no significant age effects on prevalence.

\section{DISCUSSION}

This article examined the factor structure of ADHD symptoms in adults 18-75 years of age in a community sample in The Netherlands. Confirmatory factor analyses provided strong support that the three-factor model with factors IA, $\mathrm{H}$, and I as specified in the DSM-IV and as devised for children can be generalized to adults. The three-factor structure that allowed for cross-loadings proved to be rather robust and independent of gender and could be replicated in analyses in young as well as old subjects. The internal consistency of the symptom factors was somewhat lower than that reported for parent and teacher ratings of similar factors in children (Gomez et al. 1999). Possible explanations are: (1) the inter-item correlations in adults are less inflated by gender and age effects; (2) symptom levels are lower in adults (Biederman et al. 2000) and due to lower symptom levels, the inter-item correlations become smaller (Van den Oord \& Van der Ark, 1997); and (3) adult self-ratings are less affected by rater bias.

Although the confirmatory factor analyses favoured the three-factor over the two-factor solution, this is not equivalent to say that the two-factor model is invalid. The two-factor model in its turn had a significantly better fit than the one-factor model, and seems to be an acceptable model for the organization of the diagnostic symptoms of ADHD in adults. This implies that the division of the 18 ADHD symptoms into IA and HI domains for diagnosis as described in DSM-IV is reasonably appropriate in adults. The greater difference between the two-factor and three-factor models in adults than in children (Gomez et al. 1999) seems to be related to the different role of I symptoms in adults compared to that in children. In order to found future editions of the DSM classification of ADHD, the three-factor model should be further investigated in older age groups.

The external validity of the ADHD symptom factors in adults was apparent from meaningful and substantial correlations with the GHQ-28 and its subscales and with measures of self-rated psychosocial impairment. The IA and $\mathrm{H}$ symptom factors contributed significantly and independently to the prediction of the self-assessed presence of a psychological disorder after adjusting for the influence of general psychopathology, as indexed by the GHQ-28. The correlations of the childhood symptoms with the adult IA, $\mathrm{H}$ and I symptom factors suggest some stability of the syndrome over time, as has been shown in follow-up studies of children with ADHD derived from both clinical (Barkley et al. 1990) and community samples (Taylor et al. 1996).

A cutoff of four or more symptoms of IA or of HI was associated with a significant increase of overall psychosocial impairment, even after controlling for the influence of general psychopathology. This is lower than the cutoff of six symptoms, as derived for children in the DSM-IV Field Trial (Lahey et al. 1994). A lower threshold in adults than in children is in accordance with follow-up studies of children with ADHD (Biederman et al. 2000). These indicate that adults have on average less symptoms of ADHD than children and adolescents, but also that lower symptom levels in adults do not imply better functioning. A cutoff of six symptoms for adults may be overly restrictive and may possibly lead to under-diagnosis of ADHD in adults (Murphy \& Barkley, 1996).

Most studies in children report substantially higher scores on ADHD symptom scales for boys (Buitelaar, 2002). By contrast, in this adult study gender effects were absent for IA and I symptoms and women even had slightly higher scores for $\mathrm{H}$ symptoms. The diagnostic threshold of four symptoms also identified a slightly higher prevalence in women. Another recent epidemiological study did report a higher prevalence of adult ADHD in males than in females (Kessler, 2004), whereas studies of the prevalence of ADHD symptoms in adult licensed 
drivers (Murphy \& Barkley, 1996) and among a clinical sample of adult patients with ADHD (Kooij et al. 2001) did not find gender effects. In any case, higher scores for women on some aspects of ADHD are difficult to explain. We could rule out a confound by higher GHQ scores in women in our analysis of partial correlations. An explanation may be that ADHD symptoms in girls are relatively under-reported by significant others (i.e. parents and teachers), and that adult women themselves are rather sensitive to the presence of interfering ADHD symptoms. The issue of gender differences in $\mathrm{HI}$ is not new in fact. On the $\mathrm{I}_{7}$ impulsiveness questionnaire some studies reported slightly higher scores on impulsiveness for women (Eysenck et al. 1985), whereas other studies found equal scores for men and women (Luengo et al. 1991; Caci et al. 2003). The conclusion is that more research into the role of gender in adult ADHD is needed.

Similar conclusions apply to the role of age. $\mathrm{H}$ symptoms showed a small but significant decline over age between 18 and 75 years. This suggests that the decline of $\mathrm{H}$ that starts before age 18 years (Biederman et al. 2000) continues thereafter. No age influences were found for IA and I symptoms, a finding discrepant from that in the adult licensed drivers study (Murphy \& Barkley, 1996). In the National Cormorbidity Survey Replication in a population with an age span of 18-44 years no significant age effects were found (Kessler, 2004).

In spite of the developmental decline of $\mathrm{H}$, the HI subtype was the most prevalent one in this sample, irrespective of the threshold used. This is in accordance with previous results in adults (Murphy \& Barkley, 1996) but in contrast to findings from epidemiological studies in children and adolescents that report the inattentive type as the most prevalent one (Buitelaar, 2002).

Explanations may be that hyperactive and impulsive behaviour is relatively overrated in adults due to the use of symptom definitions designed for children, or that the self-report of adults differs qualitatively from the ratings of parents and teachers on symptoms in children, leading to a difference in distribution of symptom type. The validity of current hyperactive and impulsive symptom definitions for ADHD should, therefore, be assessed in adults.

\section{Strengths and limitations}

The present results should be interpreted in the context of the strengths and limitations of the study. Strengths included the population-based approach, the broad age range, and the fact that data were collected before the media hype about ADHD in adults started in The Netherlands and, therefore, biases were minimal. Limitations were that data on symptoms and impairment were obtained by self-report and information about ADHD in childhood was based on three core items. All findings here must be interpreted with the understanding that DSM-IV diagnostic requirements like age of onset of symptoms, pervasiveness across situations, and continuity of symptoms over time, have not been used in this analysis. The impairment assessed finally was not tailored to ADHD, i.e. did not reflect academic under-achievement or occupational problems. However, it may be reassuring to note that self-report of ADHD symptoms in adolescents tended to underrather than over-report symptom levels (Danckaerts et al. 1999). Self-report was further found to be reliable compared to that of parents and partners and reveal meaningful and predicted associations with measures of impairment and outcome (Danckaerts et al. 1999; Murphy \& Schachar, 2000; Smith et al. 2000; Mannuzza et al. 2002). However, future population-based surveys on ADHD in adults using structured interviews and incorporating specific impairment measures would be very valuable and should further clarify the role of gender and age. These studies may also address the issue of possible confound of ADHD ratings by mild symptoms of anxiety and depression by including more specific trait-like measures of these symptoms.

\section{Clinical implications}

There are several implications of the present findings that ADHD in adults between 18-75 years of age shows a similar make-up as ADHD in children and is correlated with impairment. This will broaden the focus and necessitate a reconceptualization of ADHD. It is not merely a child psychiatric disorder that persists into young adulthood, but an important and relatively unique manifestation of psychopathology across the whole lifespan. ADHD merits clinical 
and research attention in early as well as in late adulthood and to an equal degree in men and women. The threshold of six out of nine symptoms may be too restrictive to be applied to adults and merits further epidemiological research including clinical diagnosis. The particularly very identical structure of the inattentive symptom dimension in childhood, adolescence and adulthood will facilitate the study of the biological and genetic correlates of this dimension across the lifespan in the future.

\section{ACKNOWLEDGEMENTS}

The present study was supported by Mental Health Institute GGZ Delfland, Delft, by Health Care Insurance Company DSW, Schiedam, and by Parnassia, psycho-medical centre, Den Haag (Dr Kooij), Hersenstichting Nederland, Nationaal Fonds Geestelijke Volksgezondheid (Dr Buitelaar) and Praeventiefonds (28-816-2, Nijmegen Health Area Project 2, Dr Roscam Abbing and Dr Zitman), all from The Netherlands. Dr E. J. van den Oord was partly supported by grants from the US National Institute of Mental Health MH065320 and NARSAD.

\section{DECLARATION OF INTEREST}

Dr Kooij and Dr Buitelaar are both consultants to and at the speakers bureau for Janssen-Cilag and Eli Lilly and Company. Dr Buitelaar has also served as consultant to Abbott. Dr E. J. van den Oord is a consultant to GlaxoSmithKline.

\section{REFERENCES}

Akaike, H. (1987). Factor analysis and AIC. Psychometrika 52, 317-332.

Barkley, R. A., Fischer, M., Edelbrock, C. S. \& Smallish, L. (1990). The adolescent outcome of hyperactive children diagnosed by research criteria: I. An 8-year prospective follow-up study. Journal of the American Academy of Child and Adolescent Psychiatry 29, 546-557.

Barkley, R. A., Murphy, P. \& Kwasnik, D. (1996). Psychological adjustment and adaptive impairments in young adults with attention deficit hyperactivity disorder. Journal of Attention Disorders 1, $41-54$.

Baumgaertel, A., Wolraich, M. L. \& Dietrich, M. (1995). Comparison of diagnostic criteria for attention deficit disorders in a German elementary school sample. Journal of the American Academy of Child and Adolescent Psychiatry 34, 629-638.

Bentler, P. M. (1990). Comparative fit indexes in structural models. Psychological Bulletin 107, 238-246.

Biederman, J., Faraone, S. V., Spencer, T., Wilens, T., Norman, D., Lapey, K. A., Mick, E., Lehman, B. K. \& Doyle, A. (1993). Patterns of psychiatric comorbidity, cognition, and psychosocial functioning in adults with attention deficit hyperactivity disorder American Journal of Psychiatry 150, 1792-1798.

Biederman, J., Mick, E. \& Faraone, S. V. (2000). Age-dependent decline of symptoms of attention deficit hyperactivity disorder: impact of remission definition and symptom type. American Journal of Psychiatry 157, 816-818.

Browne, M. W. (1984). Asymptotically distribution free methods for the analysis of covariance structures. Britisch Journal of Mathematical and Statistical Psychology 37, 62-83.

Buitelaar, J. K. (2002). Epidemiological aspects: what have we learned over the last decade? In Hyperactivity Disorders (2 edn) (ed. S. Sandberg). Cambridge University Press, Cambridge.

Caci, H., Nadalet, L., Bayle, F. J., Robert, P. \& Boyer, P. (2003). Cross-cultural study of the Impulsiveness-VenturesomenessEmpathy Questionnaire (IVE-7). Comprehensive Psychiatry 44, 381-387.

Castellanos, F. X., Giedd, J. N., Berquin, P. C., Walter, J. M., Sharp, W., Tran, T., Vaituzis, A. C., Blumenthal, J. D., Nelson, J., Bastain, T. M., Zijdenbos, A., Evans, A. C. \& Rapoport, J. L. (2001). Quantitative brain magnetic resonance imaging in girls with attention-deficit/hyperactivity disorder. Archives of General Psychiatry 58, 289-295.

Central Bureau of Statistics (CBS) (1997). Dutch population data

Danckaerts, M., Heptinstall, E., Chadwick, O. \& Taylor, E. (1999). Self-report of attention deficit and hyperactivity disorder in adolescents. Psychopathology 32, 81-92.

Dempster, A. P., Laird, N. M. \& Rubin, D. B. (1977). Maximum likelihood from incomplete data via the EM algorithm. Journal of the Royal Statistical Society Series B 39, 1-22.

Dougherty, D. D., Bonab, A. A., Spencer, T. J., Rauch, S. L., Madras, B. K. \& Fischman, A. J. (1999). Dopamine transporter density in patients with attention deficit hyperactivity disorder. Lancet $\mathbf{3 5 4}$ 2132-2133.

DuPaul, G. J., Power, T. J., Anastopoulos, A. D. \& Reid, R. (1998) ADHD Rating Scale-IV. Checklists, Norms and Clinical Interpretation. The Guilford Press, New York.

Eysenck, S. B. G., Pearson, P. R., Easting, G. \& Allsopp, J. F. (1985). Age norms for impulsiveness, venturesomness and empathy in adults. Personality and Individual Differences 6, 613-619.

Faraone, S. V., Biederman, J. \& Monuteaux, M. C. (2000). Toward guidelines for pedigree selection in genetic studies of attention deficit hyperactivity disorder. Genetic Epidemiology 18, 1-16.

Goldberg, D. P. \& Williams, P. (1988). A Users's Guide to the General Health Questionnaire. NFER-Nelson: Windsor.

Gomez, R. J., Harvey, J., Quick, C., Scharer, I. \& Harris, G. (1999). DSM-IV AD/HD: confirmatory factor models, prevalence, and gender and age differences based on parent and teacher ratings of autralian primary school children. Journal of Child Psychology and Psychiatry 40, 265-274.

Jöreskog, K. G. (1978). Structural analysis of covariance and correlation matrices. Psychometrika 43, 443-477.

Kessler, R. C. (2004). Prevalence of Adult ADHD in the United States: results from the National Comorbidity Survey Replication (NCS-R). Presented at the 2004 Annual Meeting of the American Psychiatric Association.

Kooij, J. J. S., Aeckerlin, L. P. \& Buitelaar, J. K. (2001). Functioning, comorbidity and treatment of 141 adults with attention deficit hyperactivity disorder (ADHD) at a psychiatric outpatient department [in Dutch]. Nederlands Tijdschrift voor Geneeskunde 145, 1498-1501.

Lahey, B. B., Applegate, B., McBurnett, K., Biederman, J., Greenhill, L., Hynd, G. W., Barkley, R. A., Newcorn, J., Jensen, P. \& Richters, J. (1994). DSM-IV field trials for attention deficit hyperactivity disorder in children and adolescents. American Journal of Psychiatry 151, 1673-1685.

Lahey, B. B., Pelham, W. E., Schaughency, E. A., Atkins, M. S., Murphy, H. A., Hynd, G. W., Russo, M., Hartdagen, S. \& Lorys-Vernon, A. (1988). Dimensions and types of attention deficit disorder. Journal of the American Academy of Child and Adolescent Psychiatry 27, 330-335. 
Luengo, M. A., Carillo-De-La-Pena, M. T. \& Otero, J. M. (1991). The components of impulsiveness: a comparison of the I.7 impulsiveness questionnaire and the Barratt impulsiveness scale. Personality and Individual Differences 12, 657-667.

Mannuzza, S., Klein, R. G., Bessler, A., Malloy, P. \& LaPadula, M. (1993). Adult outcome of hyperactive boys. Educational achievement, occupational rank, and psychiatric status. Archives of General Psychiatry 50, 565-576.

Mannuzza, S., Klein, R. G., Klein, D. F., Bessler, A. \& Shrout, P. (2002). Accuracy of adult recall of childhood attention deficit hyperactivity disorder. American Journal of Psychiatry 159, 1882-1888.

Marsh, H. W., Balla, J. R. \& McDonald, R. P. (1988). Goodnessof-fit indexes in confirmatory factor analysis: the effect of sample size. Psychological Bulletin 103, 391-410.

Murphy, K. (1996). Adults with attention deficit hyperactivity disorder: assessment and treatment considerations. Seminars in Speech and Language 17, 245-253.

Murphy, K. \& Barkley, R. A. (1996). Prevalence of DSM-IV symptoms of ADHD in adult licensed drivers: Implications for clinical diagnosis. Journal of Attention Disorders 3, 147-161.

Murphy, P. \& Schachar, R. (2000). Use of self-ratings in the assessment of symptoms of attention deficit hyperactivity disorder in adults. American Journal of Psychiatry 157, 1156-1159.

Múthen, L. K. \& Múthen, B. O. (1998). Mplus: Users's Guide. Múthen \& Múthen: Los Angeles.

Pelham Jr., W. E., Gnagy, E. M., Greenslade, K. E. \& Milich, R. (1992). Teacher ratings of DSM-III-R symptoms for the disruptive behavior disorders. Journal of the American Academy of Child and Adolescent Psychiatry 31, 210-218.

Satorra, A. \& Bentler, P. M. (1988). Scaling corrections for chisquare statistics in covariance structure analysis. Proceedings of the Business and Economic Statistics Section of the American Statistical Association, pp. 308-313. American Statistical Association: Alexandria, VA.
Smith, B. H., Pelham Jr., W. E., Gnagy, E., Molina, B. \& Evans, S. (2000). The reliability, validity, and unique contributions of selfreport by adolescents receiving treatment for attention-deficit/ hyperactivity disorder. Journal of Consulting and Clinical Psychology 68, 489-499.

Spencer, T., Wilens, T., Biederman, J., Faraone, S. V., Ablon, J. S. \& Lapey, K. (1995). A double-blind, crossover comparison of methylphenidate and placebo in adults with childhood-onset attention-deficit hyperactivity disorder. Archives of General Psychiatry 52, 434-443.

Taylor, E., Chadwick, O., Heptinstall, E. \& Danckaerts, M. (1996). Hyperactivity and conduct problems as risk factors for adolescent development. Journal of the American Academy of Child and Adolescent Psychiatry 35, 1213-1226.

Van den Oord, E. J. \& Van der Ark, L. A. (1997). A note on the use of the Tobit approach for tests scores with floor or ceiling effects. British Journal of Mathematical and Statistical Psychology 50, 351-364.

Weiss, G., Hechtman, L. \& Milroy, Th. (1985). Psychiatric status of hyperactives as adults: a controlled prospective 15-year follow-up of 63 hyperactive children. Journal of the American Academy of Child Psychiatry 24, 211-220.

Wilens, T. E., Biederman, J., Prince, J., Spencer, T. J., Faraone, S. V., Warburton, R., Schleifer, D., Harding, M., Linehan, C. \& Geller, D. (1996). Six-week, double-blind, placebo-controlled study of desipramine for adult attention deficit hyperactivity disorder. American Journal of Psychiatry 153, 1147-1153.

Williams, L. J. \& Holahan, P. J. (1994). Parsimony-based fit indices for multiple indicator models: do they work? Structural Equation Modeling 1, 161-189.

Zametkin, A. J., Nordahl, T. E., Gross, M., King, A. C., Semple, W. E., Rumsey, J., Hamburger, S. \& Cohen, R. M. (1990). Cerebral glucose metabolism in adults with hyperactivity of childhood onset. New England Journal of Medicine 323 1361-1366. 